\title{
Nck1 depletion induces activation of the PI3K/Akt pathway by attenuating PTP1B protein expression
}

\author{
Hui Li, Julie Dusseault and Louise Larose
}

\begin{abstract}
Background: Activation of the PI3K/Akt pathway mediates crucial cellular functions regulated by receptor tyrosine kinases, such as cell growth, proliferation, survival and metabolism. Previously, we reported that the whole-body knockout of the Src homology domain-containing adaptor protein Nck1 improves overall glucose homeostasis and insulin-induced activation of the PI3K/Akt pathway in liver of obese mice. The aim of the current study is to elucidate the mechanism by which Nck1 depletion regulates hepatic insulin signaling.

Results: Here, we demonstrate that Nck1 regulates the activation of the PI3K/Akt pathway in a protein tyrosine phosphatase 1B (PTP1B)-dependent mechanism. Indeed, depletion of Nck1 by siRNA in HepG2 cells enhances PI3K-dependent basal and growth factor-induced Akt activation. In accordance, primary hepatocytes isolated from $\mathrm{Nck}^{-1-}$ mice also display enhanced Akt activation in response to insulin. Activation of the PI3K/Akt pathway in Nck1-depleted HepG2 cells relies on higher levels of tyrosine-phosphorylated proteins and correlates with decreased PTP1B levels. Interestingly, Nck1 and PTP1B in cells are found in a common molecular complex and their interaction is dependent on the SH3 domains of Nck1. Finally, Nck1 depletion in HepG2 cells neither affects PTP1B gene transcription nor PTP1B protein stability, suggesting that Nck1 modulates PTP1B expression at the translational level.

Conclusion: Our study provides strong evidence supporting that the adaptor protein Nck1 interacts with PTP1B and also regulates PTP1B expression. In this manner, Nck1 plays a role in regulating the PI3K/Akt pathway.
\end{abstract}

Keywords: Nck1, PTP1B, PI3K/Akt pathway

\section{Background}

The serine/threonine protein kinase Akt plays an essential role in regulating various critical cellular functions, such as cell growth, proliferation, survival and metabolism [1]. Activation of Akt involves PI3K, which converts PIP2 to PIP3 following its interaction with receptor tyrosine kinases (RTKs) or tyrosine-phosphorylated (pY) substrates of RTKs [2]. PIP3 recruits the protein kinase PDK1 and Akt at the plasma membrane where Akt gets activated through phosphorylation within the activation loop at $\mathrm{Thr}^{308}$ by PDK1 [3]. However, full activation of Akt requires additional phosphorylation at $\operatorname{Ser}^{473}$ by mTORC2 [4].

Insulin signaling is initiated by binding of insulin to the insulin receptor (IR) tyrosine kinase, which results in IR activation through autophosphorylation on tyrosine residues and then tyrosine phosphorylation of insulin

\footnotetext{
* Correspondence: louise.larose@mcgill.ca

Department of Medicine, Polypeptide Laboratory, McGill University and The Research Institute of McGill University Health Centre, Montreal, QC, Canada
}

receptor substrates (IRSs) such as IRS-1. This leads to activation of the PI3K/Akt pathway via binding of $\mathrm{p} 85$, the regulatory subunit of PI3K, to IRS-1 [5]. Numerous studies have demonstrated that impaired insulin signaling is closely associated with insulin resistance concomitant with obesity and type 2 diabetes [6,7]. PTP1B, the prototype of non-receptor tyrosine phosphatase superfamily, has been demonstrated to negatively regulate insulin signaling using whole-body or tissue-specific PTP1B knockout mice [8-12]. At the molecular level, PTP1B counteracts both IR and IRS-1 tyrosine phosphorylation to inhibit insulin signaling $[13,14]$.

In mammals, the Src homology (SH) domain-containing adaptor protein Nck (non-catalytic region of tyrosine kinase) includes two highly identical members, Nck1 and Nck2, which contain exclusively three SH3 domains at the $\mathrm{N}$-terminus and one SH2 domain at the C-terminus [15]. Originally, Nck was associated with actin cytoplasmic reorganization through coupling RTKs or RTK substrates to downstream effectors regulating cytoskeleton dynamics 
[16]. We previously reported that Nck1 is involved in regulating translation through its interaction with the $\beta$ subunit of the eukaryotic initiation factor 2 [17] and more recently, it was shown that Nck1 functions in cap homeostasis by assembling the cytoplasmic capping complex [18]. Furthermore, in agreement with its localization at the endoplasmic reticulum (ER) network [19], we demonstrated that Nck1 is also involved in regulating the unfolded protein response (UPR) [19-22], a signaling network initiated to cope with stress induced by accumulation of unfolded or misfolded proteins in the ER [23]. Supporting this, we reported that diet-induced obese $\mathrm{Nck}^{-/-}$mice display improved overall glucose homeostasis and enhanced hepatic insulin signaling that correlates with reduced UPR compared to obese $\mathrm{Nck}^{+/+}$ littermates [24]. Using the human hepatocellular carcinoma cell line HepG2, we also showed that Nck1 depletion by siRNA promotes insulin signaling, as represented by increased levels of pY IRS-1, Akt phosphorylation on $\mathrm{Ser}^{473}$, GSK3 $\beta$ phosphorylation on $\mathrm{Ser}^{9}$ and glycogen synthesis in response to insulin [24].

In the present study, we investigate the mechanism by which Nck1 depletion regulates hepatic insulin signaling. Interestingly, we found that in addition to promoting insulin signaling, Nck1 depletion by siRNA in HepG2 cells also enhances basal and other growth factor-induced Akt phosphorylation, which correlates with increased global pY protein levels and decreased PTP1B levels. In addition, we demonstrated that Nck1 interacts with PTP1B through its SH3 domains, and modulates PTP1B protein expression likely at the translational level. Overall, we uncover a role for Nck1 in regulating activation of the PI3K/Akt pathway through a PTP1B-dependent mechanism.

\section{Results}

\section{Nck1 depletion enhances hepatic Akt phosphorylation} and downstream signaling

Previously, we reported a role for Nck1 in regulating hepatic insulin signaling both in vivo and in vitro [24]. In fact, in liver of obese $N c k 1^{-/-}$mice and in HepG2 cells depleted of Nck1 by siRNA, we observed increased Akt phosphorylation on $\mathrm{Ser}^{473}$ in response to insulin compared to controls. Here, we showed that transient transfection of HepG2 cells with Nck1 siRNA, which resulted in more than $90 \%$ reduction in Nck1 protein levels, led to enhanced insulin-induced Akt phosphorylation on the activation site $\mathrm{Thr}^{308}$ (Figure 1A). To confirm a role for Nck1 in regulating insulin-induced Akt activation in a more physiological setting, primary hepatocytes isolated from normal chow diet (NCD)-fed $N c k 1^{+/+}$and $N c k 1^{-/-}$ mice were stimulated or not with insulin and total cell lysates assessed for Akt phosphorylation by immunoblot. Interestingly, primary hepatocytes from $N c k 1^{-1-}$ mice also displayed increased insulin-induced Akt phosphorylation on $\mathrm{Ser}^{473}$ and $\mathrm{Thr}^{308}$ compared to $\mathrm{Nck1}^{+/+}$hepatocytes (Figures $1 \mathrm{~B}$ and $\mathrm{C}$ ). Although this might be attributed to higher Akt levels in $\mathrm{Nck1}^{-/-}$hepatocytes (Figure 1D), the absolute levels of phosphorylated Akt (pAkt), the bona fide signaling molecule, were significantly increased in $N c k 1^{-/-}$hepatocytes upon insulin stimulation, as shown by higher pAkt $\mathrm{Ser}^{473} / \beta$-Actin ratio compared to $\mathrm{Nck} 1^{+/+}$ hepatocytes (Figure 1E). Together, these data demonstrate that Nck1 is a regulator of insulin-induced Akt phosphorylation.

The transcription factor forkhead box O1 (FoxO1) is known to translocate from the nucleus to the cytosol upon phosphorylation by Akt [25]. To test whether signaling downstream of Akt is upregulated in Nck1-depleted HepG2 cells, we assessed FoxO1 subcellular distribution by immunofluorescence and confocal microscopy. In serum-starved control HepG2 cells, FoxO1 accumulated in the nucleus, whereas nuclear FoxO1 was hardly seen in Nck1-depleted HepG2 cells (Figure 1F), supporting dynamic Akt downstream signaling in these cells. Since phosphorylation of FoxO1 by Akt is well known to limit hepatic glucose production through decreasing transcription of the glucose 6-phosphatase gene [26], we then compared the ability of insulin to inhibit glucose production in HepG2 cells transfected with control or Nck1 siRNA. In accordance with increased Akt activation and cytoplasmic localization of FoxO1, we found that Nck1-depleted HepG2 cells also displayed higher sensitivity toward the inhibitory effect of insulin on glucose production (Figure 1G).

To delineate the mechanism by which Nck1 regulates hepatic Akt phosphorylation, we determined whether Nck1 depletion promotes Akt phosphorylation in response to other growth factors. For this, we compared epidermal growth factor (EGF)- and platelet-derived growth factor (PDGF)-induced Akt phosphorylation in HepG2 cells depleted or not of Nck1. In cells transfected with control siRNA, EGF induced Akt phosphorylation on both $\mathrm{Ser}^{473}$ and $\mathrm{Thr}^{308}$ at $10 \mathrm{nM}$, while $1 \mathrm{nM}$ of EGF dramatically enhanced Akt phosphorylation on both sites only in Nck1-depleted cells (Figure 2A). Enhanced Akt phosphorylation was also observed in Nck1-depleted cells treated with PDGF (Figure 2B). Interestingly, we constantly observed increased basal Akt phosphorylation in Nck1depleted cells. To further confirm the negative regulation of Nck1 on basal Akt phosphorylation, we tested two other siRNAs to decrease Nck1 expression in HepG2 cells. As shown in Figure $2 \mathrm{C}$, these two siRNAs, which inhibited Nck1 expression by $62 \%$ (Nck1-1) and 94\% (Nck1-2) respectively, also enhanced basal Akt phosphorylation on both $\mathrm{Ser}^{473}$ and $\mathrm{Thr}^{308}$. These findings demonstrate that the effects of Nck1 depletion on promoting Akt phosphorylation are not limited to growth factor-induced Akt phosphorylation, but also apply to basal Akt phosphorylation. 


\section{A}

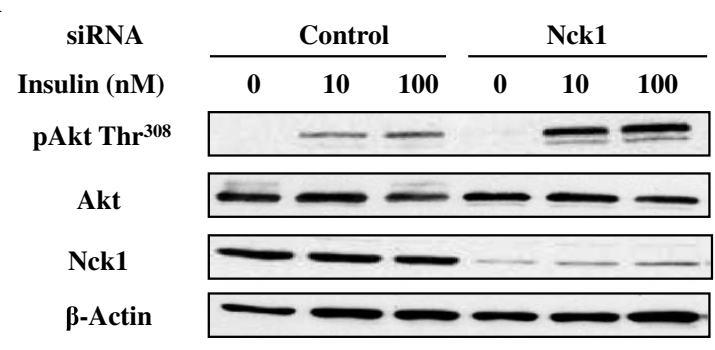

B

\begin{tabular}{|c|c|c|c|c|c|}
\hline \multirow[b]{2}{*}{ Insulin (nM) } & \multicolumn{2}{|c|}{$\mathrm{NckI}^{+/+}$} & \multicolumn{2}{|c|}{ Nckl-/ } & \multirow[b]{2}{*}{$\mathrm{NckI}^{+/+} \mathrm{NckI}^{-/-}$} \\
\hline & $\mathbf{0}$ & 10 & $\mathbf{0}$ & 10 & \\
\hline pAkt $\operatorname{Ser}^{473}$ & \multicolumn{4}{|c|}{$--\cdots$} & $-\infty$ \\
\hline pAkt Thr ${ }^{308}$ & 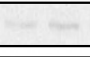 & - & - & -- & $-\infty-\infty$ \\
\hline
\end{tabular}

Akt

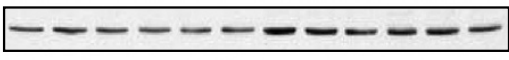

$\beta$-Actin

C

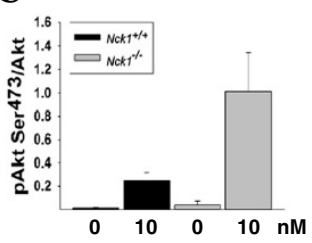

D

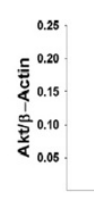

$\mathbf{E}$

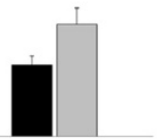

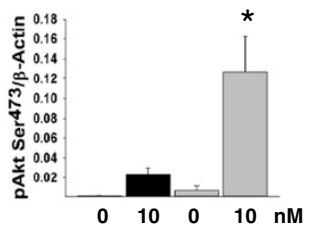

$\mathbf{F}$
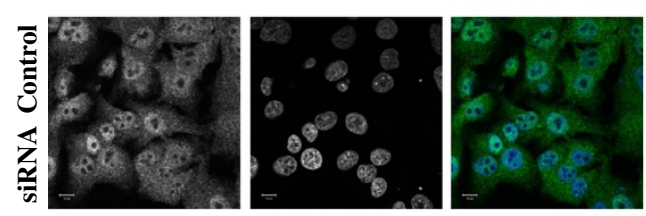

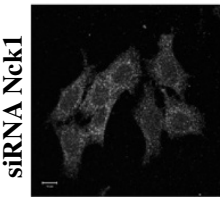

FoxO1

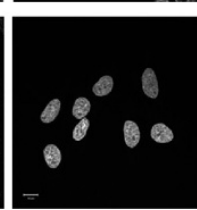

DAPI
G

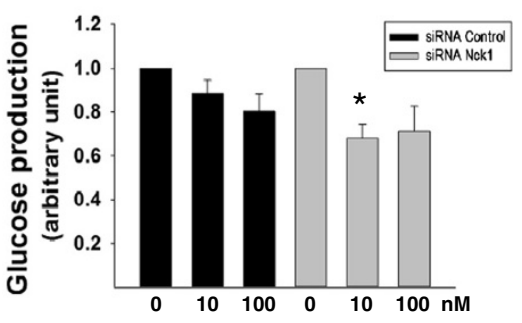

Merged

Figure 1 Insulin-induced Akt phosphorylation and downstream signaling are enhanced in Nck1-depleted cells. (A) HepG2 cells transfected with control or Nck1 siRNA were exposed to 0,10 and $100 \mathrm{nM}$ insulin for $5 \mathrm{~min}$ after an overnight serum starvation. Equal amount of proteins from total cell lysates were subjected to immunoblot with indicated antibodies. (B) Primary hepatocytes isolated from Nck $1^{+/+}$and $\mathrm{Nck} 1^{-/-}$mice were left untreated or treated with $10 \mathrm{nM}$ insulin for $5 \mathrm{~min}$. Equal amount of proteins from total cell lysates were subjected to immunoblot with indicated antibodies. Bar charts represent mean \pm SEM of the ratio of pAkt/total Akt (C), Akt/ $\beta$-Actin (D) or pAkt/B-Actin (E) quantified by densitometry analysis. Data are representative of three independent experiments with similar results. ${ }^{*} \mathrm{P}<0.05$ versus $\mathrm{Nck}^{+/+}$. (F) Representative confocal images of control or Nck1 siRNA-transfected HepG2 cells stained with FoxO1 antibody and DAPI. Images acquired at 63X magnification are representative of three independent experiments with similar results. Scale bars equal $10 \mu \mathrm{m}$. (G) HepG2 cells transfected with control or Nck1 siRNA were exposed to 0,10 and $100 \mathrm{nM}$ insulin and analyzed for glucose production by measuring glucose levels in glucose-free DMEM. Glucose production was normalized according to protein contents and expressed as relative value compared to basal. Bar chart represents mean \pm SEM from six independent experiments performed in triplicate. ${ }^{*} \mathrm{P}<0.05$ versus siRNA control.

Collectively, these results strongly support that Nck1 regulates hepatic Akt activation.

Nck protein family includes two members sharing 68\% identity, Nck1 and Nck2. Here we showed that HepG2 cells also expressed Nck2 and surprisingly, Nck1 depletion in HepG2 cells resulted in upregulation of Nck2 expression (Figure 3A). To determine whether increased Nck2 levels contributes to the effect of Nck1 depletion on Akt 


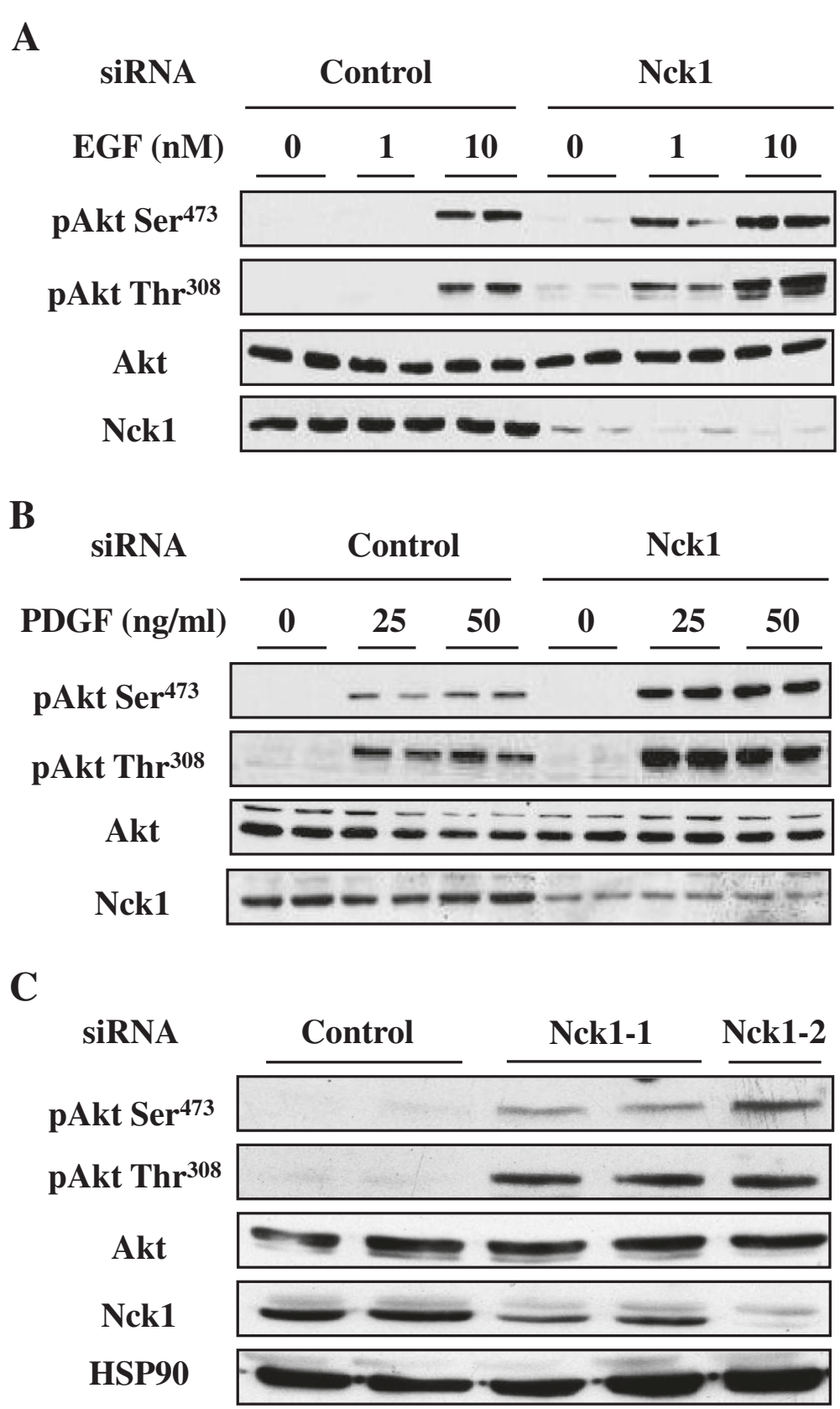

Figure 2 EGF- and PDGF-induced Akt phosphorylation is enhanced in Nck1-depleted HepG2 cells. Overnight serum-starved HepG2 cells transfected with control or Nck1 siRNA were exposed to 0, 1 and $10 \mathrm{nM} \mathrm{EGF} \mathrm{(A)} \mathrm{or} \mathrm{0,} 25$ and 50 ng/ml PDGF-BB (B) for 5 min. Equal amount of proteins from total cell lysates were subjected to immunoblot with indicated antibodies. Data are representative of three independent experiments performed in duplicate with similar results. (C) HepG2 cells transfected with control or different Nck1 siRNAs (Nck1-1, Nck1-2) were starved overnight. Equal amount of proteins from total cell lysates were subjected to immunoblot with indicated antibodies. Data are representative of three independent experiments showing similar results.

phosphorylation, Nck2 was overexpressed in HepG2 cells and Akt phosphorylation assessed. As shown in Figure 3B, overexpression of Nck2 in HepG2 cells had no effect on basal and insulin-induced phosphorylation of Akt, excluding that elevated Nck2 expression is involved in enhanced phosphorylation of Akt in Nck1-depleted HepG2 cells. On the other hand, overexpression of Nck1 in HepG2 cells also had no effect on Akt phosphorylation (Figure 3C). This may be attributed to the fact that Nck1 is an adaptor protein with various binding partners and its overexpression, by perturbing Nck1 interactome homeostasis, does not essentially lead to the opposite effects of silencing Nck1. 


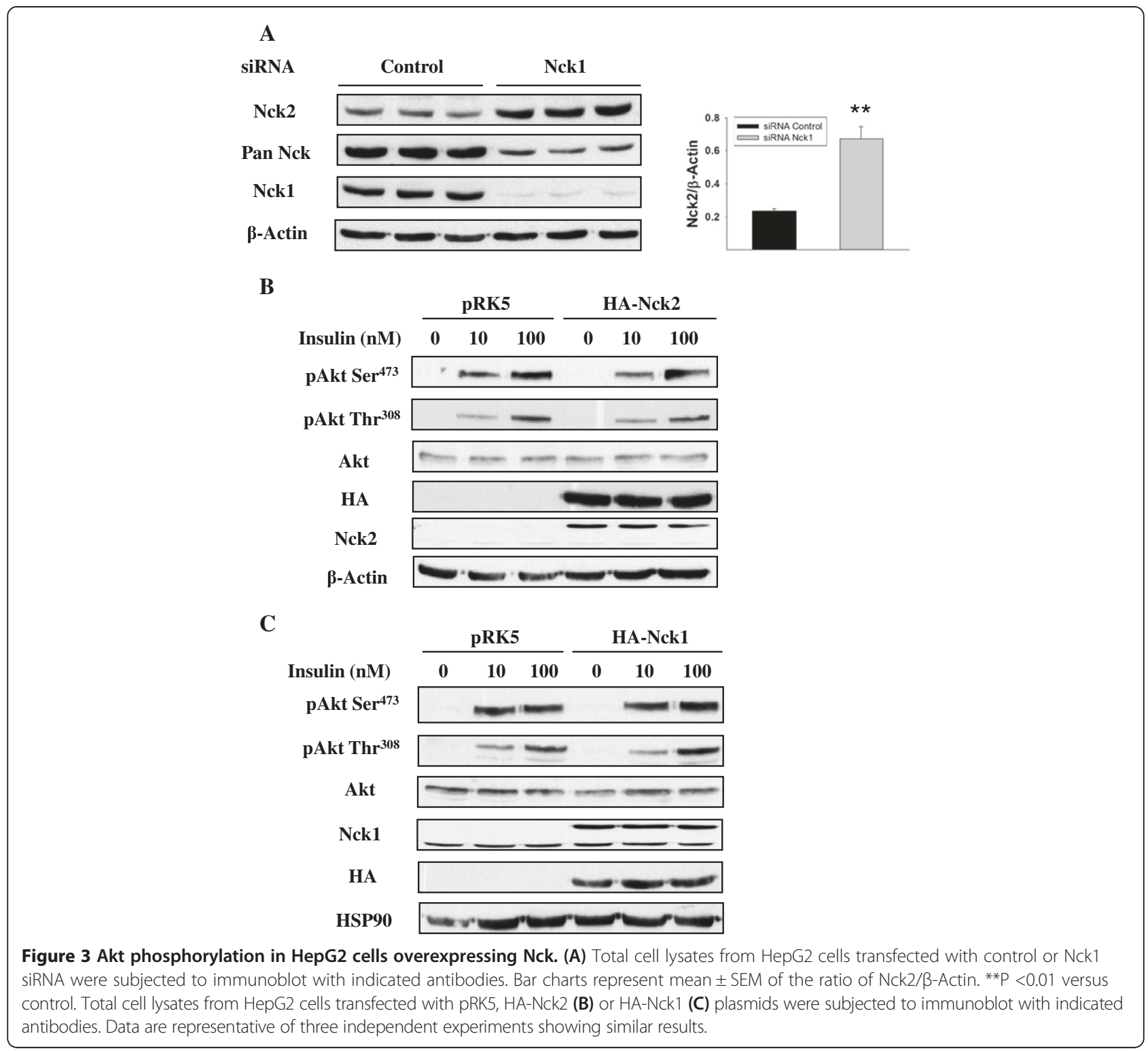

\section{Enhanced basal Akt phosphorylation in Nck1-depleted HepG2 cells is PI3K-dependent}

Given that PI3K is an upstream activator of Akt, we assessed whether PI3K mediates the effects of Nck1 depletion on basal Akt phosphorylation. HepG2 cells transfected with control or Nck1 siRNA were treated with the PI3K inhibitor LY294002 and cell lysates subjected to immunoblot to detect Akt phosphorylation. We found that LY294002 completely abolished the elevated basal Akt phosphorylation on $\mathrm{Ser}^{473}$ and $\mathrm{Thr}^{308}$ in Nck1-depleted cells (Figure 4A), suggesting that activation of PI3K mediates enhanced Akt phosphorylation in these cells. PI3K mainly gets activated following the association of its regulatory subunit p85 with $\mathrm{pY}$ proteins, such as activated RTKs and RTK substrates phosphorylated on tyrosine residues [27]. Thus, we analyzed pY protein levels in control and Nck1 siRNA-transfected HepG2 cells pretreated or not with pervanadate (PV), a general tyrosine phosphatase inhibitor [28]. In the absence of pervanadate, pY protein levels were increased in Nck1-depleted cells (Figure 4B) compared to control while PV treatment amplified this difference (Figure $4 \mathrm{C}$ ). In addition, we observed increased levels of pY proteins associated with the p85 subunit of PI3K in Nck1-depleted cells compared to cells transfected with control siRNA (Figure 4D). Altogether, these data indicate that Nck1 depletion promotes PI3Kdependent Akt phosphorylation in HepG2 cells. Furthermore, this correlates with increased levels of $\mathrm{pY}$ proteins and $\mathrm{pY}$ proteins associated with $\mathrm{p} 85$, suggesting that Nck1 regulates signaling upstream of PI3K. 


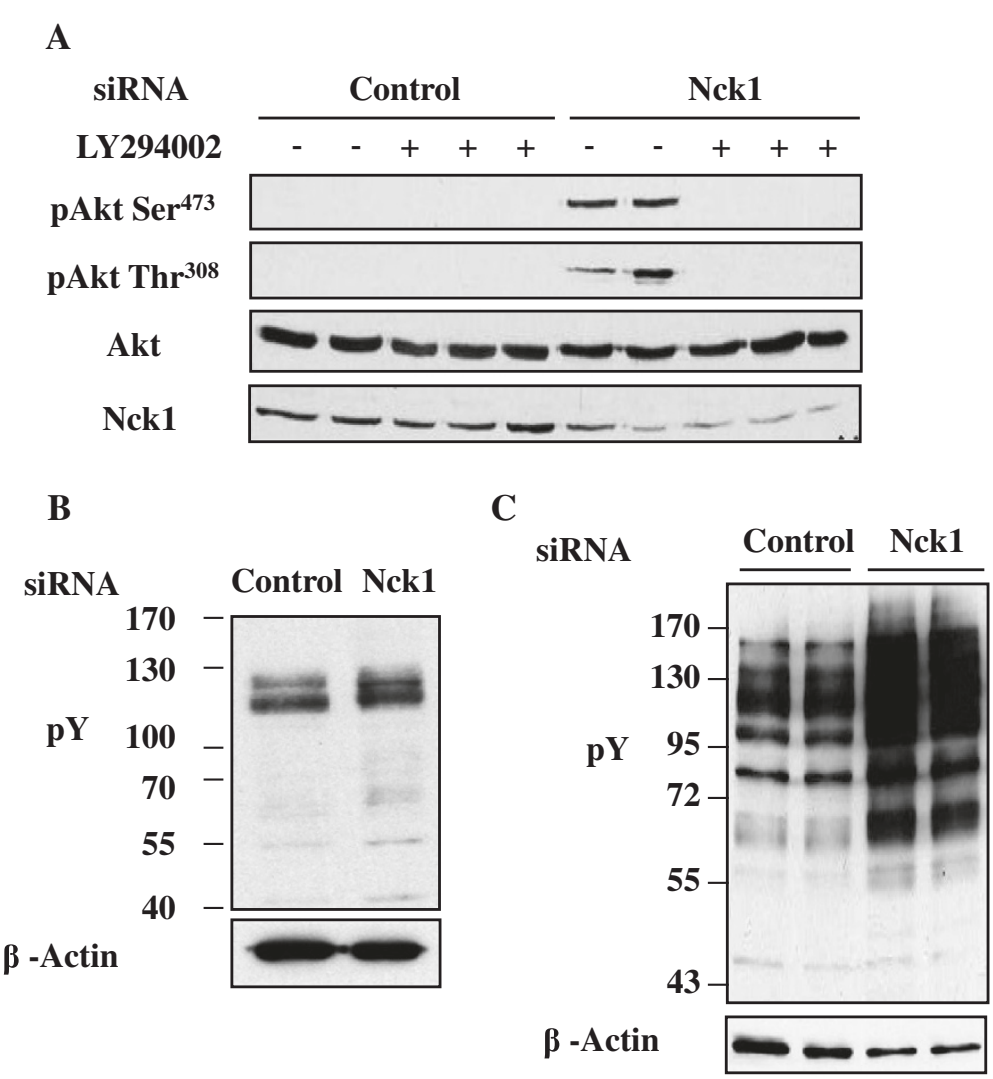

D

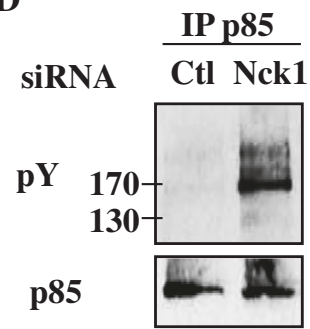

Figure 4 Enhanced basal Akt phosphorylation in HepG2 cells depleted of Nck1 is dependent on PI3K, and correlates with increased total and p85-associated pY proteins. Overnight serum-starved HepG2 cells transfected with control or Nck1 siRNA were exposed to $10 \mu \mathrm{M}$ of the PI3K inhibitor LY294002 for 30 min (A), untreated (B) or pretreated with $100 \mu \mathrm{M}$ of pervanadate (PV) for 5 min (C) before harvesting. Equal amount of proteins from total cell lysates were subjected to immunoblot with indicated antibodies. Data are representative of three independent experiments performed in duplicate or triplicate and showing similar results. Total cell lysates prepared from HepG2 cells transiently transfected with control or Nck1 siRNA were subjected to anti-p85 (regulatory subunit of PI3K) immunoprecipitation followed by immunoblot using indicated antibodies (D). Data are representative of three independent experiments showing similar results.

Nck1 interacts with PTP1B through its SH3 domains PTP1B is known to negatively regulate RTK signaling that leads to activation of the PI3K/Akt pathway. Interaction between PTP61F and Dock, the orthologue of PTP1B and Nck in Drosophila melanogaster, was demonstrated using the yeast two-hybrid system and then confirmed by in vitro binding assays [29]. In this study, we assessed Nck1/PTP1B interaction in mammalian cells. First, we used HEK293 cells transiently overexpressing HA-Nck1 and FLAG-PTP1B given that compared to HepG2 cells, HEK293 cells can be transfected at higher efficiency. As shown in Figure 5A, in HEK293 cells overexpressing both Nck1 and PTP1B, we detected PTP1B in the HA immunoprecipitates, indicating that Nck1 and PTP1B exist in a common complex when overexpressed. Next, we showed that endogenous Nck coimmunoprecitated with FLAG-PTP1B transiently overexpressed in HEK293 cells (Figure 5B). Finally, in both HEK293 and HepG2 cells, we provided evidence that Nck and PTP1B interacted at the endogenous level (Figure 5C). 
A

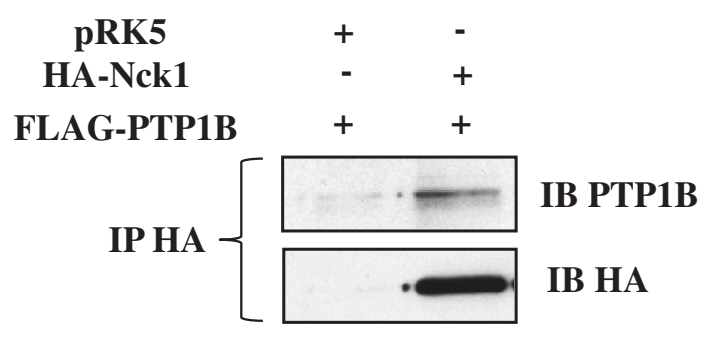

TCL

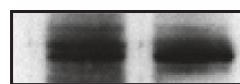

IB PTP1B

B
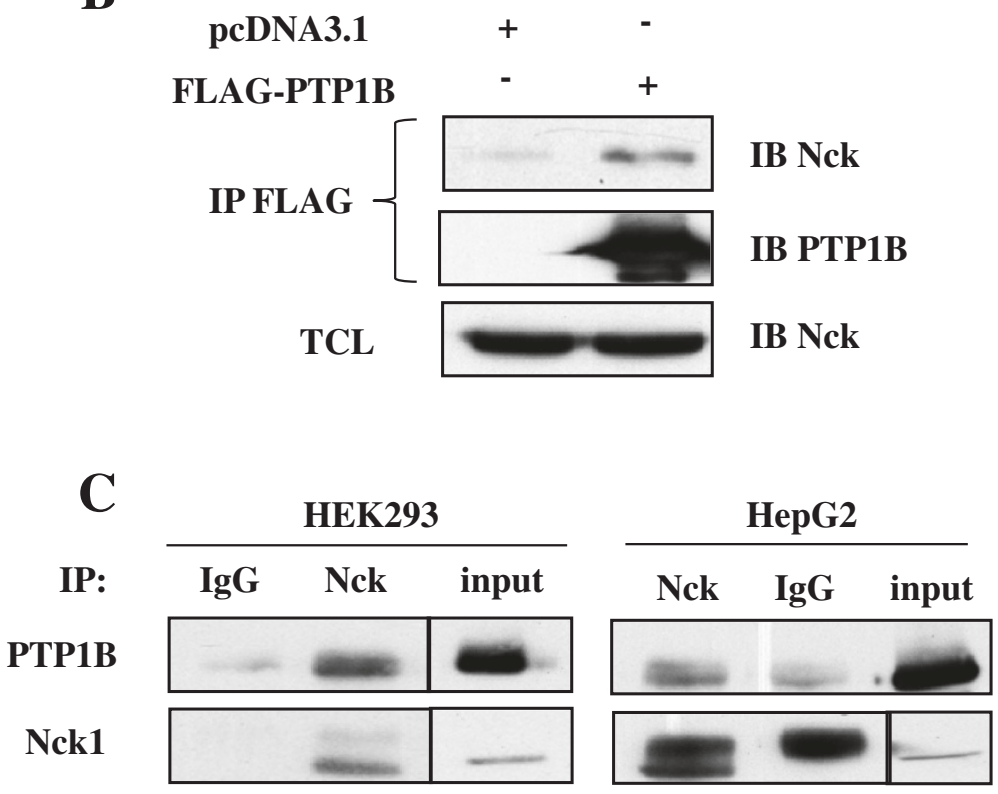

D

\section{GST Nck1 SH2 SH3 input}

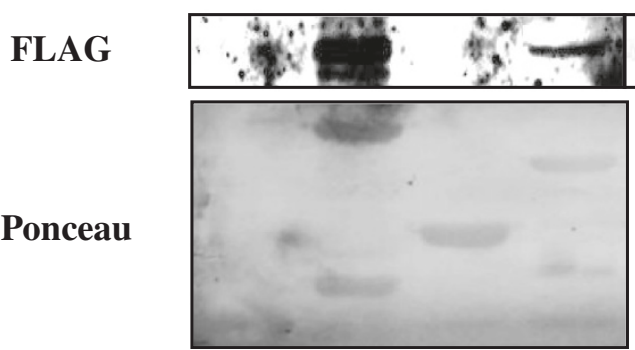

Figure 5 Nck and PTP1B interaction. (A) HEK293 cells were transfected with FLAG-PTP1B and pRK5 (empty vector) or HA-Nck1. Total cell lysates were subjected to anti-HA immunoprecipitation followed by immunoblot using indicated antibodies. Data are representative of three independent experiments showing similar results. (B) HEK293 cells were transfected with FLAG-PTP1B and pcDNA3.1 (empty vector). Total cell lysates were subjected to anti-FLAG immunoprecipitation followed by immunoblot using indicated antibodies. (C) Total cell lysates from HEK293 or HepG2 cells were subjected to lgG or Nck immunoprecipitation followed by immunoblot with indicated antibodies. The vertical line in the immunoblot is to indicate that samples are separated by empty lanes. (D) Cell lysates from HEK293 cells overexpressing FLAG-PTP1B were incubated with GST, GST-Nck1, GST-SH2 domain of Nck1, GST-SH3 domains of Nck1 for $3 \mathrm{~h}$ followed by immunoblot with anti-FLAG antibody. Ponceau staining reveals the GST-fusion proteins. Data are representative of three independent experiments showing similar results. 
To identify Nck1 molecular determinant(s) that mediates its interaction with PTP1B, we performed in vitro binding assays using bacterial recombinant GST fusion proteins of Nck1 full-length, $\mathrm{SH} 2$ or $\mathrm{SH} 3$ domains. Lysates prepared from HEK293 cells overexpressing FLAG-PTP1B were incubated with the above GST fusion proteins. As a result, full-length Nck1 and the SH3 domains bind to PTP1B, while the $\mathrm{SH} 2$ domain failed to do so (Figure 5D). Overall, these data demonstrate that Nck1 interacts with PTP1B through its SH3 domains in mammalian cells.

\section{PTP1B expression is downregulated in Nck1-depleted HepG2 cells}

Given that Nck1 interacts with PTP1B, we hypothesized that Nck1 regulates activation of the PI3K/Akt pathway through PTP1B. To test this, we determined PTP1B levels in HepG2 cells transfected with control or Nck1
siRNA. As shown in Figure 6A, PTP1B levels were decreased in HepG2 cells depleted of Nck1. This was confirmed using two other Nck1 siRNAs (Figure 6B). Of note, downregulation of PTP1B levels seemed to correlate well with the extent of Nck1 knockdown. Interestingly, PTP1B levels were robustly decreased in liver of NCDfed $\mathrm{Nck1}^{-/-}$mice compared with $\mathrm{Nck1}^{+/+}$littermates (Figure 6C), strongly supporting our in vitro observation. Overall, these data suggest that reduced PTP1B levels contribute to promote activation of the PI3K/Akt pathway in Nck1-depleted cells. Supporting this, we found that Akt phosphorylation was increased in $P T P 1 B^{-/-}$MEFs (Figure 7A). In accordance, total $\mathrm{pY}$ protein levels were increased in $P T P 1 B^{-/-}$compared to $P T P 1 B^{+/+}$MEFs, and this difference was even more pronounced in PV-treated cells (Figure 7B). Interestingly, in Nck1 siRNA-transfected HepG2 cells, reintroducing expression of Nck1 by overexpressing a siRNA-resistant form of Nck1 prevented

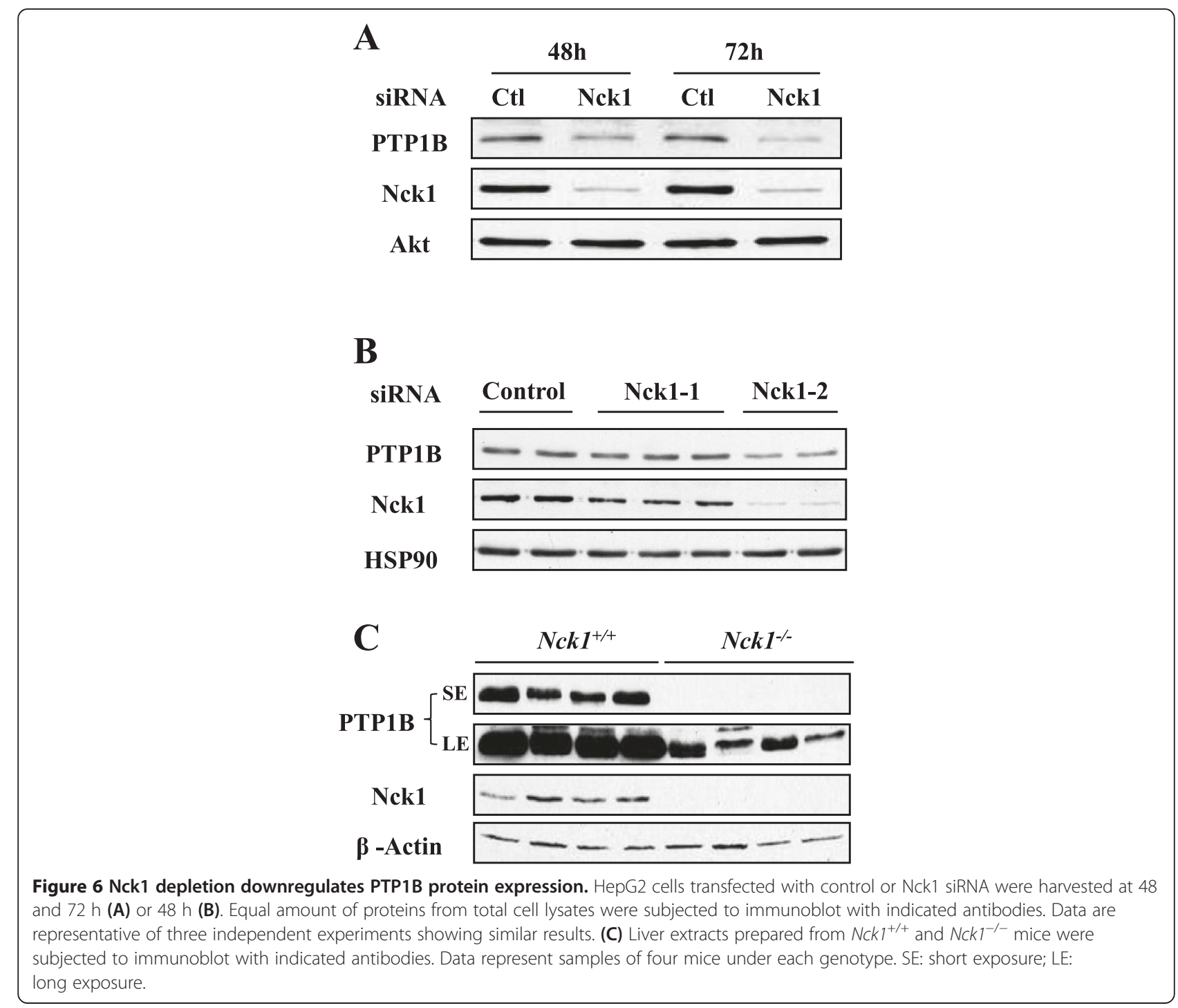




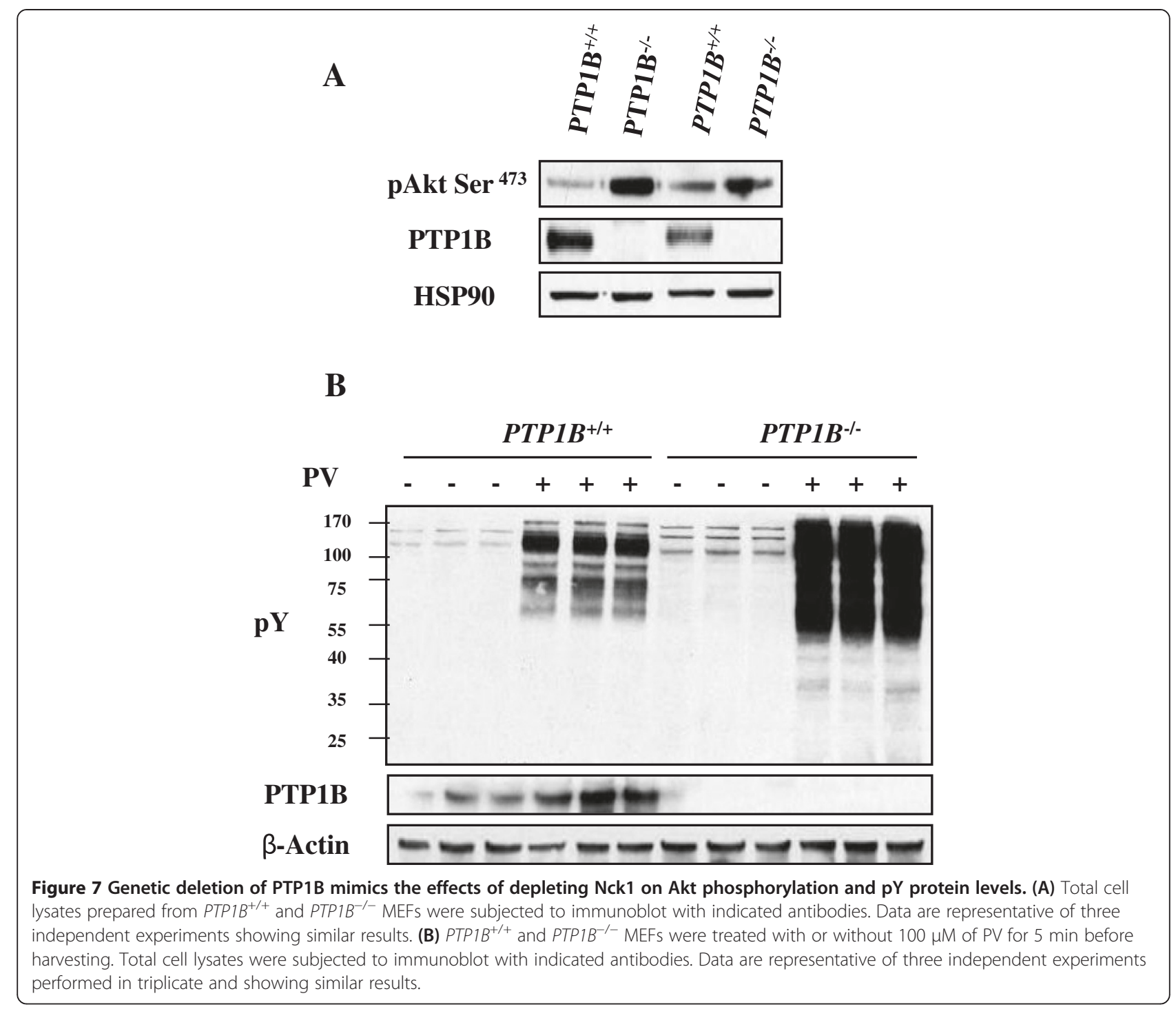

increased phosphorylation of Akt and restored PTP1B levels (Figure 8). Collectively, these results strongly suggest that Nck1 regulates activation of the PI3K/Akt pathway through a PTP1B-dependent mechanism.

To investigate the mechanism by which Nck1 depletion decreases PTP1B protein expression, we then compared PTP1B mRNA levels by quantitative realtime PCR (qRT-PCR) on total RNA extracts prepared from HepG2 cells transfected with control or Nck1 siRNA. As shown in Figures 9A, qRT-PCR analyses demonstrated that depletion of Nck1 did not significantly reduce PTP1B mRNA levels. This result was confirmed using liver extracts from $N c k 1^{+/+}$and $N c k 1^{-/-}$ mice (Figure 9B). Therefore, altered PTP1B gene transcription is not involved in reducing PTP1B protein expression in Nck1-depleted HepG2 cells and liver of $N c k 1^{-1-}$ mice.
Previously, it was shown that Akt phosphorylates PTP1B on Ser $^{50}$ and impairs its ability to dephosphorylate the IR [30]. To ensure that increased Akt activation does not affect PTP1B expression in Nck1-depleted cells, HepG2 cells transfected with control or Nck1 siRNA were treated with the PI3K inhibitor LY294002 or specific Akt inhibitor Akti 1/2 to block Akt activity and cell lysates subjected to immunoblot to detect PTP1B expression. Inhibiting PI3K or Akt did not restore PTP1B expression in Nck1-depleted cells (Figure 9C), suggesting that decreased PTP1B levels in the absence of Nck1 is independent of activation of the PI3K/Akt pathway.

Next, we examined whether depleting Nck1 in HepG2 cells alters PTP1B protein stability. Using cycloheximide, a compound that blocks translation elongation [31], we found that PTP1B protein turnover rate remained the 


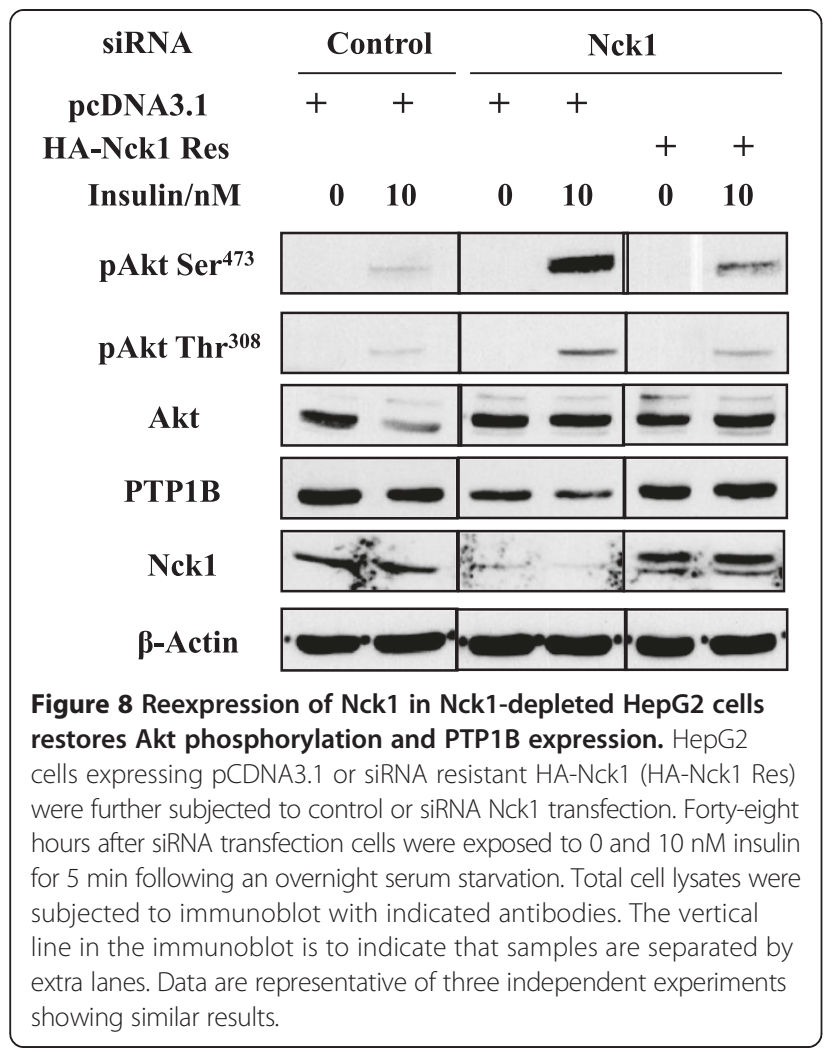

same after depleting Nck1 (Figure 9D), suggesting that protein degradation is not involved in PTP1B downregulation induced by Nck1 depletion. Indeed, neither blocking proteasome-dependent protein degradation by MG132 nor blocking lysosome-dependent protein degradation by chloroquine restored PTP1B expression in Nck1-depleted cells (Figures 9E and F), confirming that reduced PTP1B expression in Nck1-depleted cells is not due to protein degradation. Overall, these data suggest that Nck1 regulates PTP1B protein expression at the translational level.

\section{Discussion}

Previously, we reported that the whole-body Nck1 knockout improves overall glucose homeostasis in obese mice, in agreement with enhanced hepatic insulin signaling [24]. Besides, we uncovered that siRNAmediated Nck1 depletion in HepG2 cells also enhances insulin signaling. These data strongly suggest that Nck1 is a regulator of hepatic insulin signaling. However, the mechanism by which Nck1 depletion regulates hepatic insulin signaling remains to be elucidated. In the present study, we report that in addition to insulin-induced Akt phosphorylation, Nck1 depletion also impacts Akt phosphorylation in serum-starved (basal) HepG2 cells and in response to other growth factors such as EGF and PDGF. Furthermore, we demonstrate that elevated Akt phosphorylation in Nck1-depleted HepG2 cells correlates with higher levels of total pY proteins and pY proteins associated with the p85 subunit of PI3K. Meanwhile, we find that Nck1 interacts with PTP1B and regulates its protein expression. Taken together, these data let us propose that Nck1 depletion, by reducing PTP1B expression, enhances tyrosine-phosphorylated proteins that trigger PI3K activation, therefore promoting Akt phosphorylation.

PTP1B is a negative regulator of insulin signaling by dephosphorylating IR and IRS proteins [13,32]. In accordance, whole-body $P T P 1 B$ knockout mice are hypersensitive to insulin and resistant to high fat diet (HFD)-induced insulin resistance [8,9]. In cultured primary human skeletal muscle, manipulating PTP1B expression levels inversely modulates insulininduced Akt phosphorylation, and increased PTP1B expression in skeletal muscle of patients with type 2 diabetes is associated with decreased whole-body insulin sensitivity [33]. Moreover, PTP $1 B^{-/-}$MEFs display marked increase in tyrosine-phosphorylated EGFR [34] and PDGFR [34,35]. In this study, we observe lower PTP1B levels in HepG2 cells depleted of Nck1, which we believe contribute to promote protein tyrosine phosphorylation and activation of the PI3K/Akt pathway, as supported by elevated basal pY protein levels and Akt phosphorylation in MEFs lacking PTP1B. However, the underlying PTP1B substrate(s) that regulates Akt phosphorylation in Nck1depleted cells remain to be determined, although IR, IRS, EGFR and PDGFR are all well-known targets of PTP1B. Considering the localization of PTP1B at the cytoplasmic face of the ER [36], reduced PTP1B levels in Nck1-depleted cells might induce activation of the PI3K/Akt pathway in a ligand-independent manner by promoting phosphorylation of newly synthesized RTKs during their processing, as reported for the insulin receptor precursors at the ER [37].

Localized at the ER, PTP1B has been involved in the regulation of the UPR initiated upon ER stress [38-40]. Interestingly, we previously demonstrated that Nck1 also localizes at the ER and regulates the UPR [19-22,24]. The UPR is mainly composed of three arms triggered by distinct ER transmembrane proteins: inositol-requiring enzyme $1 \alpha$ (IRE1 $\alpha$ ), protein kinase R-like ER kinase (PERK) and activating transcription factor 6 (ATF6) [23]. Recently, obesity-induced insulin resistance in peripheral insulin target tissues has been linked to ER stress that results in abnormal activation of the UPR [41-43]. In fact, obesity leads to sustained activation of IRE1 $\alpha$ that impairs insulin signaling through IRE1 $\alpha /$ JNK-mediated phosphorylation of IRS-1 that 
A

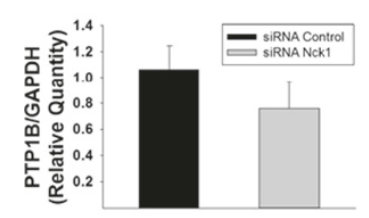

B

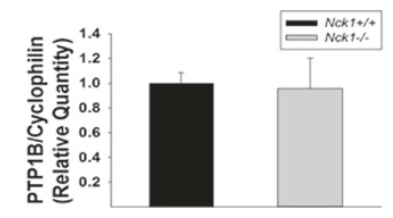

C

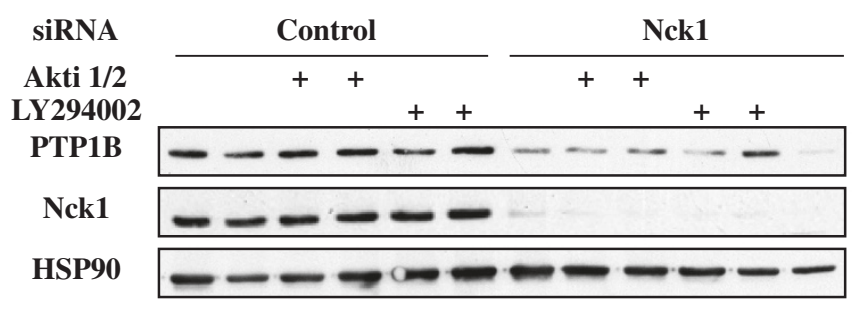

D
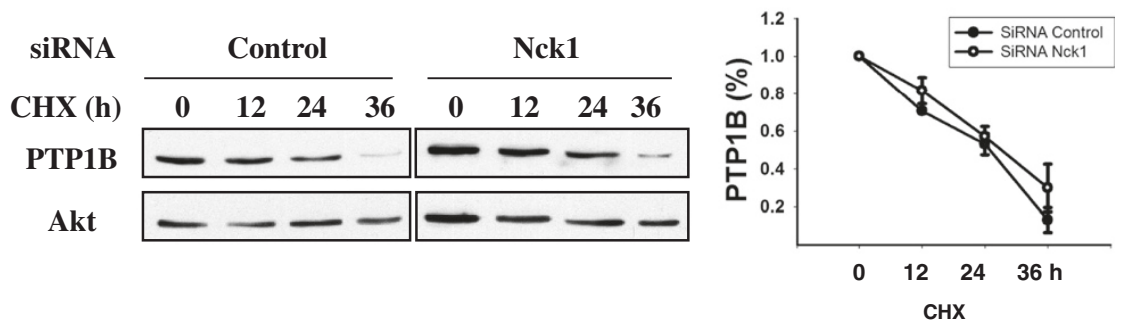

$\mathbf{E}$

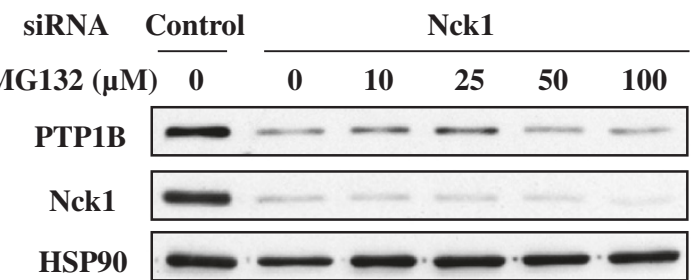

$\mathbf{F}$

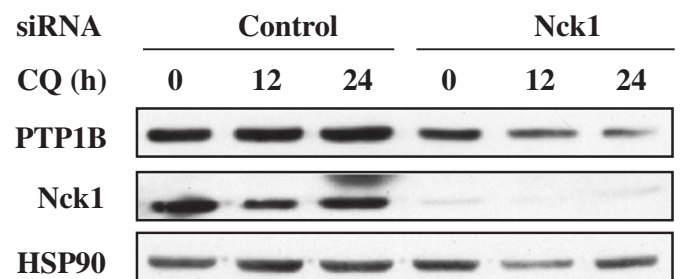

Figure 9 Nck1 depletion affects neither PTP1B gene transcription nor protein stability. (A) Quantitative RT-PCR analysis of PTP1B mRNA levels in HepG2 cells transfected with control or Nck1 siRNA. Data are presented as mean \pm SEM from five independent experiments. The expression levels of PTP1B mRNA in control siRNA-transfected cells were set to one. (B) Quantitative RT-PCR analysis of PTP1B mRNA levels in liver of Nck $7^{+/+}$and $\mathrm{NCk} 1^{-/-}$mice. Data are presented as mean \pm SEM of four mice under each genotype. The expression levels of PTP1B mRNA in Nck $1^{+/+}$mice were set to one. (C) HepG2 cells transfected with control or Nck1 siRNA were treated with $10 \mu \mathrm{M}$ of the PI3K inhibitor LY294002 or $10 \mu \mathrm{M}$ of the Akt inhibitor Akti $1 / 2$ for $24 \mathrm{~h}$ before harvesting. Equal amount of proteins from total cell lysates were subjected to immunoblot with indicated antibodies. Data are representative of three independent experiments performed in duplicate and showing similar results. (D) Twelve hours after transfection, HepG2 cells transfected with control or Nck1 siRNA were treated with $100 \mu \mathrm{g} / \mathrm{ml}$ of cycloheximide (CHX) for additional 12, $24 \mathrm{or} 36 \mathrm{~h}$. Equal amount of proteins from total cell lysates were subjected to immunoblot with indicated antibodies. The graph represents PTP1B levels at different times of CHX exposure as mean \pm SEM from three independent experiments with PTP1B levels at time 0 in control and Nck1 siRNA-transfected cells fixed to one. (E) HepG2 cells transfected with control or Nck1 siRNA were treated with 0, 10, 25, 50 and $100 \mu \mathrm{M}$ MG132 for $6 \mathrm{~h}$. Equal amount of proteins from total cell lysates were subjected to immunoblot with indicated antibodies. Data are representative of three independent experiments showing similar results. (F) HepG2 cells transfected with control or Nck1 siRNA were treated with $100 \mu \mathrm{M}$ chloroquine (CQ) for 12 or $24 \mathrm{~h}$. Equal amount of proteins from total cell lysates were subjected to immunoblot with indicated antibodies. Data are representative of three independent experiments showing similar results. 
prevents IRS-1 tyrosine phosphorylation by activated IR [42]. Whole-body Nck1 knockout mice are resistant to HFD-induced insulin resistance and ER stress, resembling the phenotype of liver-specific $P T P 1 B$ knockout mice $[11,24,44]$. Given that Nck1 interacts with PTP1B and modulates PTP1B protein expression as we demonstrate here, it is plausible that the protective effect of Nck1 deficiency against HFDinduced insulin resistance and ER stress could be attributed to PTP1B downregulation in liver of $\mathrm{Nck1}^{-1-}$ mice.

The interaction between PTP1B and Nck was first reported in Drosophila melanogaster, and suggested to involve the SH3 domains of Dock, the Nck orthologue $[29,45,46]$. This is consistent with the fact that the Cterminus of PTP1B harbors two proline-rich sequences that match the consensus $\mathrm{SH} 3$ domain-binding motif [47,48]. In mammalian cells, Nck1 associates with PTP1B independent of insulin stimulation, suggesting a SH3mediated interaction as well [49]. In this study, we provide clear evidence showing that Nck1 interacts with PTP1B through its SH3 domains. Further experiments are required to characterize which $\mathrm{SH} 3$ domain(s) is responsible for this interaction.

In the current study, we demonstrate that PTP1B protein levels are drastically decreased in Nck1-depleted HepG2 cells and liver of $N c k 1^{-/-}$mice. Interestingly, a recent study reports that $P T P 1 B^{-/-}$mice fed a NCD or HFD, both display significantly lower levels of Nck1 in skeletal muscle, although the underlying mechanism has not been investigated [50]. Therefore, a reciprocal regulation between Nck1 and PTP1B may exist. Our findings suggest that Nck1 modulates PTP1B expression at the translational level. In fact, qRT-PCR analysis reveals no change of PTP1B gene transcription in HepG2 cells depleted of Nck1 or in $N c k 1^{-/-}$liver. Using the proteasome inhibitor MG132 or lysosome inhibitor chloroquine, we rule out an effect of Nck1 depletion on PTP1B protein degradation. Furthermore, PTP1B is known to be cleaved at the C-terminal ER-targeting domain by the cysteine protease calpain, releasing a $42 \mathrm{kDa}$ soluble form of PTP1B in the cytosol [51]. Decrease in PTP1B protein levels in Nck1-depleted cells is not attributed to the C-terminal cleavage of PTP1B, since the anti-PTP1B antibody used in this study is raised against its $\mathrm{N}$-terminus, therefore would detect the cleaved form of PTP1B. Taken together, it is then possible that Nck1 affects PTP1B mRNA translation. In agreement with our previous observation that Nck1 modulates protein translation [20], we observed a decrease in general protein synthesis in HepG2 cells depleted of Nck1 as measured by ${ }^{35} \mathrm{~S}$-Met/Cyst incorporation (unpublished data). However, given that numerous protein levels (e.g. Akt, $\beta$-actin, HSP90), as determined by immunoblot, are not affected in the Nck1-depleted HepG2 cells, Nck1 might play an essential role in maintaining proper translation of specific
mRNAs such as PTP1B mRNA. Considering the essential role of Nck1 in assembling the cytoplasmic capping complex [18], it is plausible that depletion of Nck1 results in accumulation of uncapped PTP1B transcripts that are not efficiently translated. Further investigation is required to test this hypothesis. Alternatively, microRNAs, by binding to their target mRNAs, act as posttranscriptional regulators to repress target mRNA translation [52]. Searching TargetScan database reveals several putative microRNA binding sites on the 3'-UTR of human PTP1B mRNA, including miR-1, miR-206, miR-613, miR-124, miR-506, etc. Interestingly, IRE1 $\alpha$ branch of the UPR is involved in decreasing microRNA expression either through the IRE1 $\alpha$ endoribonuclease activity [53-55] or in a JNKdependent manner [56]. Considering that Nck1 depletion attenuates IRE1 $\alpha / J N K$ signaling [24], further experiments will be performed to determine whether Nck1 depletion affects PTP1B protein expression by indirectly increasing microRNAs that target PTP1B mRNA.

\section{Conclusions}

Our study highlights the implication of PTP1B in mediating Nck1-dependent regulation of the hepatic PI3K/Akt pathway. Since Akt is a critical node in regulating insulin and growth factor biological actions, our findings contribute to identify Nck1 as a potential target in therapeutic strategies for insulin resistance and cancer. Furthermore, the striking effects of PTP1B on metabolic diseases and cancer in preclinical research make it an attractive drug target. However, the development of PTP1B inhibitors is halted by selectivity and bioavailability of these drugs $[57,58]$. Given the ability of Nck1 to regulate PTP1B expression, Nck1 could be a substitutive target to bypass the bottleneck of developing PTP1B inhibitors.

\section{Methods}

\section{Cell culture and treatments}

Human hepatocellular carcinoma cells (HepG2) were grown in minimum essential Eagle's medium (MEM; GIBCO) containing 10\% fetal bovine serum (FBS; GIBCO) and $1 \%$ antibiotic-antimycotic (anti-anti) solution, which contains $10,000 \mathrm{U} / \mathrm{ml}$ of penicillin, $10,000 \mu \mathrm{g} / \mathrm{ml}$ of streptomycin, and $25 \mu \mathrm{g} / \mathrm{ml}$ of Fungizone ${ }^{\circ}$ (GIBCO). Human embryonic kidney (HEK) 293 cells, PTP1B wild type $\left(P T P 1 B^{+/+}\right)$and knockout $\left(P T P 1 B^{-/-}\right)$mouse embryonic fibroblasts (MEFs) were grown in Dulbecco's modified Eagle's medium (DMEM; GIBCO) containing 10\% FBS and $1 \%$ anti-anti. Cells were incubated at $37^{\circ} \mathrm{C}$ in a $5 \%$ $\mathrm{CO}_{2}$ environment. Small interference (si) RNAs against human Nck1 (Nck1) 5'-AACAUCCAUUACAUCUCCUU UCUCGAA-3', (Nck1-1) 5'-GGAGAUGUAAUGGAU GU UA-3', (Nck1-2) 5'-GGCCUUCACUCACUGGAAA-3' were purchased from Integrated DNA Technologies. Scramble siRNA purchased from Ambion was used as 
negative control. HepG2 cells were transfected using Lipofectamine RNAiMAX reagent (Invitrogen) according to the manufacturer's instructions, with a final siRNA concentration of $40 \mathrm{nM}$. HA-Nck1 and HA-Nck2 overexpression in HepG2 cells were performed using Lipofectamine 2000 according to the manufacturer's instructions. Reexpression of siRNA resistant HA-Nck1 in Nck1 siRNAtransfected HepG2 cells using Lipofectamine 3000 was performed $24 \mathrm{~h}$ prior siRNA transfection according to the manufacturer's instructions. HEK293 cells were transfected with empty vector, HA-Nck1 and/or FLAG-rat PTP1B using CalPhos ${ }^{\mathrm{Tu}}$ mammalian transfection kit (Clontech) according to the manufacturer's instructions. HepG2 cells were starved overnight in MEM containing $0.1 \%$ bovine serum albumin (BSA, Invitrogen) after $48 \mathrm{~h}$ siRNA transfection, and then incubated with either insulin (Eli Lilly Co., Indianapolis, IN), EGF (Fitzgerald Industries International), PDGF-BB (Roche), pervanadate (Sgima), LY294002 (Calbiochem) or Akt inhibitor 1/2 (Calbiochem) at concentrations indicated in Figure legends. Cycloheximide (Calbiochem), MG132 (Calbiochem) or chloroquine diphosphate salt (Sigma) were added to HepG2 cells after siRNA transfection without starvation at concentrations indicated in Figure legends.

\section{Mice}

$\mathrm{Nck}^{+/-}$mice were previously obtained from Dr. Tony Pawson (Toronto, Canada) [59] and used to generate $\mathrm{Nck1}^{+/+}$and $\mathrm{Nck1}^{-/-}$littermates. Mice were maintained in an animal facility with fixed $12 \mathrm{~h}$ light/dark cycle and free access to water and food. All animal care and handling followed the guidelines of McGill University (protocol \#5069) according to the standards defined by the Canadian Council on Animal Care. Only male mice were used in this study.

\section{Liver extracts and isolated primary hepatocytes}

Age-matched mice were used to harvest liver or prepare primary hepatocytes. Mice were euthanized using a $\mathrm{CO}_{2}$ chamber, tissues immediately collected, snap-frozen in liquid nitrogen, and kept at $-80^{\circ} \mathrm{C}$ for further processing. To prepare tissue extracts, tissues were homogenized using a Polytron at $20 \%(\mathrm{w} / \mathrm{v})$ in $5 \mathrm{mM}$ Tris $\cdot \mathrm{HCl}$ (pH 7.4), $0.25 \mathrm{M}$ sucrose, $1 \mathrm{mM} \mathrm{MgCl}_{2}, 1 \mathrm{mM}$ dithiothreitol, $10 \mathrm{mM}$ sodium pyrophosphate, $1 \mathrm{mM}$ sodium orthovanadate, $100 \mathrm{mM}$ sodium fluoride, and $17.5 \mathrm{mM}$ $\beta$-glycerophosphate supplemented with protease inhibitors. Triton X-100 was added to a final concentration of $1 \%$. Following $10 \mathrm{~min}$ incubation at $4^{\circ} \mathrm{C}$, samples were centrifuged at $13,000 \mathrm{~g}$ for $10 \mathrm{~min}$ at $4^{\circ} \mathrm{C}$. Supernatants were further centrifuged at 200,000 g for $30 \mathrm{~min}$ at $4^{\circ} \mathrm{C}$. Final supernatants were subjected to Bio-Rad protein assay (Bio-Rad) for protein quantification and equal amount of protein was used for immunoblot analysis.
Mouse primary hepatocytes were isolated according to Renton et al. [60] with minor modifications. Briefly, anesthetized mice were subjected to in situ liver perfusion via a cannula inserted in the inferior vena cava through the heart's right atrium, while the portal vein was cut. Then, liver was first perfused with heparin solution $(10 \mathrm{mM}$ HEPES (pH 7.85), $142 \mathrm{mM} \mathrm{NaCl}, 6.7 \mathrm{mM} \mathrm{KCl}, 0.6 \mathrm{mM}$ EGTA and $1.5 \mathrm{U} / \mathrm{ml}$ Heparin), followed by collagenase solution (10 mM HEPES ( $\mathrm{pH} 7.85$ ), $142 \mathrm{mM} \mathrm{NaCl}$, $6.7 \mathrm{mM} \mathrm{KCl}, 12 \mathrm{mM} \mathrm{CaCl} 2 \cdot 2 \mathrm{H}_{2} \mathrm{O}$ and $200 \mathrm{U} / \mathrm{ml}$ collagenase). Perfused liver was transferred to a petri dish, gently teased apart with forceps, filtered through two layers of gauze, washed twice with MEM containing $10 \%$ FBS and antibiotics, and then plated in 6-well plates coated with collagen matrix (Vitrogen-100; Collagen Corp.). Primary hepatocytes were cultured as previously reported [61]. Insulin stimulation, carried out in serumfree media, was evaluated two days after initial plating following the conditions indicated in the Figure legends.

\section{Antibodies}

As previously described, rabbit polyclonal anti-Nck1 antibody was generated using GST-fusion protein encoding human Nck1-specific amino acid sequences between the third SH3 and the SH2 domains (Nck1: QNNPLTSGLEPSPPQCDYIRPSLTGKFAGNP) [24]. Rabbit polyclonal anti-p85 antibody was generated using GST-fusion protein encoding the two $\mathrm{SH} 2$ domains of the $\mathrm{p} 85$ subunit of PI3K. pAkt ( $\mathrm{Ser}^{473}$ and $\mathrm{Thr}^{308}$ ), Akt, FoxO1, $\beta$-Actin and HSP90 antibodies were purchased from Cell Signaling Technology. pY20 antibody was purchased from Santa Cruz Biotechnology, PTP1B antibody from BD Biosciences, anti-HA matrix from Roche, while FLAG antibodies was from Sigma.

\section{Cell lysates, immunoblot and immunoprecipitation}

Cells were washed twice with ice-cold phosphate-buffered saline (PBS) and detergent-soluble proteins were extracted using lysis buffer (50 mM HEPES (pH 7.5), $150 \mathrm{mM} \mathrm{NaCl}$, $10 \%$ glycerol, $1 \%$ Triton X-100, $1.5 \mathrm{mM} \mathrm{MgCl}_{2}, 1 \mathrm{mM}$ EGTA, $10 \mathrm{mM}$ sodium pyrophosphate, $100 \mathrm{mM}$ sodium fluoride) supplemented with protease inhibitors. Following centrifugation at $13,300 \mathrm{~g}$ for $10 \mathrm{~min}$ at $4^{\circ} \mathrm{C}$, supernatants were subjected to Bio-Rad protein assay. Total cell lysates normalized for protein were resolved by SDS-PAGE, transferred onto nitrocellulose membrane, and immunoblotted with indicated antibodies. Enhanced chemiluminescence (Amersham GE Healthcare) was used to detect immunoreactive proteins according to the manufacturer's instructions. For p85 immunoprecipitation, total cell lysates prepared from HepG2 cells were incubated with anti-p85 antibody overnight at $4{ }^{\circ} \mathrm{C}$. The next day, protein A-agarose (Santa Cruz Biotechnology) was added to the lysate-antibody mixture and samples were further incubated 
for $2 \mathrm{~h}$ at $4^{\circ} \mathrm{C}$. For Nck/PTP1B coimmunoprecipitation, total cell lysates were incubated with either anti-HA, antiFLAG or anti-Nck antibodies for $2 \mathrm{~h}$ or overnight at $4{ }^{\circ} \mathrm{C}$. Immunoprecipitated proteins were washed three times with lysis buffer, resuspended in Laemmli buffer, heated at $95^{\circ} \mathrm{C}$ for $5 \mathrm{~min}$ and freezed until analysis by immunoblot as described above.

\section{Glucose production}

HepG2 cells transfected with control or Nck1 siRNA were plated in 12-well plates. After an overnight serum starvation, cells were incubated with insulin for $6 \mathrm{~h}$. Then, media were replaced by $0.4 \mathrm{ml} /$ well of phenol red-free, glucosefree DMEM containing $2 \mathrm{mM}$ sodium pyruvate (GIBCO) and $20 \mathrm{mM}$ lactate (Sigma) in the presence of insulin for another $3 \mathrm{~h}$. Finally, these media were collected and subjected to glucose measurement by the Amplex ${ }^{\circ}$ Red glucose/glucose oxidase assay kit (Invitrogen). Glucose levels were normalized according to protein contents.

\section{GST pull-down assay}

GST, GST-Nck1 full length, GST-Nck1 SH2 domain and GST-Nck1 SH3 domain proteins induced in bacteria according to classical procedures and purified using glutathione agarose beads were mixed with total cell lysates from HEK293 cells overexpressing FLAG-PTP1B for $3 \mathrm{~h}$ at $4^{\circ} \mathrm{C}$. Following the incubation, beads were washed with lysis buffer. Proteins were recovered in Laemmli buffer and analyzed by immunoblot.

\section{Immunofluorescence and confocal microscopy}

HepG2 cells were plated on coverslips in 6-well plates and transfected with control or Nck1 siRNA. After an overnight serum starvation, cells were fixed in $4 \%$ paraformaldehyde for $15 \mathrm{~min}$. Fixed cells were blocked in PBS containing 5\% donkey serum and $0.3 \%$ Triton X-100 for $1 \mathrm{~h}$ followed by an overnight incubation with anti-FoxO1 antibody at $4{ }^{\circ} \mathrm{C}$. The next day, cells were incubated with Alexa Fluor 488 donkey anti-rabbit $\operatorname{IgG}(\mathrm{H}+\mathrm{L})$ (Invitrogen) for $1 \mathrm{~h}$ at room temperature followed by the nuclear staining with 4, 6-diamidino-2-phenylindole dihydrochloride (DAPI, Sigma). Coverslips were mounted on glass slides using ProLong ${ }^{\circ}$ Gold antifade reagent (Invitrogen). Images were captured using a Zeiss LSM 510 confocal microscope.

\section{RNA extraction and quantitative real-time PCR}

Total RNA was extracted from transfected HepG2 cells or liver of $\mathrm{Nck1}^{+/+}$and $\mathrm{Nck1}^{-/-}$mice using TRIzol reagent (Invitrogen) according to the manufacturer's instructions. RNA was reverse transcribed to cDNA using High Capacity cDNA Reverse Transcription Kit (Life Technologies $\left.^{\mathrm{nt}}\right)$. Human PTP1B gene in HepG2 cells was amplified using Taqman $^{\circ}$ Fast Advanced Master Mix
(Life Technologies ${ }^{\mathrm{Tx}}$ ) in the ViiA ${ }^{\mathrm{Tx}} 7$ Real-Time PCR system (Life Technologies ${ }^{\mathrm{Tw}}$ ), while mouse PTP1B gene in liver extracts was amplified using Power SYBR ${ }^{\circ}$ Green PCR Master Mix (Life Technologies ${ }^{\mathrm{Tm}}$ ). Primer sequences used for mouse PTP1B gene were: forward 5'-TGGCCACAGCAAGAAGAAAA-3' and reverse 5'GGAAATGCAGGATCTCTCGA-3'. GAPDH and cyclophilin were used as internal control.

\section{Statistical analyses}

Quantification of immunoreactive signal was performed using the analysis software Quantity One (Bio-Rad) on a GS-800 Calibrated Densitometer (BIO-RAD). Results are presented as means \pm SEM. Student's $t$-test statistical analyses (unpaired) were performed using SigmaPlot Version 12 (Systat Software Inc.). P value $<0.05$ was considered to be statistically significant.

\section{Abbreviations}

RTKs: Receptor tyrosine kinases; IRS: Insulin receptor substrate; IR: Insulin receptor; ER: Endoplasmic reticulum; FoxO1: Forkhead box O1; EGF: Epidermal growth factor; PDGF: Platelet-derived growth factor; GST: Glutathione S-transferase; IRE1a: Inositol-requiring enzyme 1a; PERK: Protein kinase R-like ER kinase; ATF6: Activating transcription factor 6; JNK: cJun N-terminal kinase; NCD: Normal chow diet; HFD: High fat diet; UTR: Untranslated region; UPR: Unfolded protein response.

\section{Competing interests}

The authors declare that they have no competing interests.

\section{Authors' contributions}

$\mathrm{HL}$ and $\mathrm{LL}$ contributed to the conception and design of the study. $\mathrm{HL}$ performed the experiments, analyzed the data and prepared the manuscript. JD contributed to the experiments. All authors read and approved the final manuscript.

\section{Acknowledgements}

We thank Dr. Tony Pawson (Samuel Lunenfeld Research Institute, Toronto) for providing the $\mathrm{Nck}^{+/-}$mice. We are grateful to Victor Dumas (McGill University) and Dr. Bing Li (McGill University) for technical assistance in preparing primary hepatocytes and aRT-PCR respectively. Also, we thank Dr. Michel Tremblay (McGill University) for providing PTP1B MEFs. This work was supported by a grant from Canadian Institutes of Health Research (MOP-115045) to LL. HL is supported in part by a doctoral studentship from the RI-MUHC. JD is supported by a postdoctoral fellowship from the Canadian Diabetes Association.

Received: 4 June 2014 Accepted: 19 October 2014

Published online: 14 November 2014

\section{References}

1. Manning BD, Cantley LC: AKT/PKB signaling: navigating downstream. Cell 2007, 129(7):1261-1274.

2. Vivanco I, Sawyers CL: The phosphatidylinositol 3-Kinase AKT pathway in human cancer. Nat Rev Cancer 2002, 2(7):489-501.

3. Alessi DR, James SR, Downes CP, Holmes AB, Gaffney PR, Reese CB, Cohen P: Characterization of a 3-phosphoinositide-dependent protein kinase which phosphorylates and activates protein kinase Balpha. Curr Biol 1997, 7(4):261-269.

4. Sarbassov DD, Guertin DA, Ali SM, Sabatini DM: Phosphorylation and regulation of Akt/PKB by the rictor-mTOR complex. Science 2005, 307(5712):1098-1101.

5. Taniguchi CM, Emanuelli B, Kahn CR: Critical nodes in signalling pathways: insights into insulin action. Nat Rev Mol Cell Biol 2006, 7(2):85-96.

6. Tonks KT, Ng Y, Miller S, Coster AC, Samocha-Bonet D, Iseli TJ, Xu A, Patrick E, Yang JY, Junutula JR, Modrusan Z, Kolumam G, Stockli J, Chisholm DJ, James DE, Greenfield JR: Impaired Akt phosphorylation in insulin-resistant 
human muscle is accompanied by selective and heterogeneous downstream defects. Diabetologia 2013, 56(4):875-885.

7. Shao J, Yamashita H, Qiao L, Friedman JE: Decreased Akt kinase activity and insulin resistance in C57BL/KsJ-Leprdb/db mice. J Endocrinol 2000, 167(1):107-115.

8. Elchebly M, Payette P, Michaliszyn E, Cromlish W, Collins S, Loy AL, Normandin D, Cheng A, Himms-Hagen J, Chan CC, Ramachandran C, Gresser MJ, Tremblay ML, Kennedy BP: Increased insulin sensitivity and obesity resistance in mice lacking the protein tyrosine phosphatase-1B gene. Science 1999, 283(5407):1544-1548.

9. Klaman LD, Boss O, Peroni OD, Kim JK, Martino JL, Zabolotny JM, Moghal N, Lubkin M, Kim YB, Sharpe AH, Stricker-Krongrad A, Shulman GI, Neel BG, Kahn BB: Increased energy expenditure, decreased adiposity, and tissue-specific insulin sensitivity in protein-tyrosine phosphatase 1B-deficient mice. Mol Cell Biol 2000, 20(15):5479-5489.

10. Delibegovic M, Bence KK, Mody N, Hong EG, Ko HJ, Kim JK, Kahn BB, Neel BG: Improved glucose homeostasis in mice with muscle-specific deletion of protein-tyrosine phosphatase 1B. Mol Cell Biol 2007, 27(21):7727-7734.

11. Delibegovic M, Zimmer D, Kauffman C, Rak K, Hong EG, Cho YR, Kim JK, Kahn BB, Neel BG, Bence KK: Liver-specific deletion of protein-tyrosine phosphatase 1B (PTP1B) improves metabolic syndrome and attenuates diet-induced endoplasmic reticulum stress. Diabetes 2009, 58(3):590-599.

12. Owen C, Czopek A, Agouni A, Grant L, Judson R, Lees EK, Mcllroy GD, Goransson O, Welch A, Bence KK, Kahn BB, Neel BG, Mody N, Delibegovic M: Adipocyte-specific protein tyrosine phosphatase $1 B$ deletion increases lipogenesis, adipocyte cell size and is a minor regulator of glucose homeostasis. PloS one 2012, 7(2):e32700.

13. Goldstein BJ, Bittner-Kowalczyk A, White MF, Harbeck M: Tyrosine dephosphorylation and deactivation of insulin receptor substrate-1 by protein-tyrosine phosphatase $1 \mathrm{~B}$. Possible facilitation by the formation of a ternary complex with the Grb2 adaptor protein. J Biol Chem 2000, 275(6):4283-4289.

14. Salmeen A, Andersen JN, Myers MP, Tonks NK, Barford D: Molecular basis for the dephosphorylation of the activation segment of the insulin receptor by protein tyrosine phosphatase 1B. Mol Cell 2000, 6(6):1401-1412.

15. Lettau M, Pieper J, Janssen O: Nck adapter proteins: functional versatility in T cells. Cell Commun Signal 2009, 7:1.

16. Li W, Fan J, Woodley DT: Nck/Dock: an adapter between cell surface receptors and the actin cytoskeleton. Oncogene 2001, 20(44):6403-6417.

17. Kebache S, Zuo D, Chevet E, Larose L: Modulation of protein translation by Nck-1. Proc Natl Acad Sci U S A 2002, 99(8):5406-5411.

18. Mukherjee C, Bakthavachalu B, Schoenberg DR: The cytoplasmic capping complex assembles on adapter protein nck1 bound to the proline-rich C-terminus of Mammalian capping enzyme. PLoS Biol 2014, 12(8):e1001933.

19. Latreille M, Larose L: Nck in a complex containing the catalytic subunit of protein phosphatase 1 regulates eukaryotic initiation factor 2alpha signaling and cell survival to endoplasmic reticulum stress. J Biol Chem 2006, 281(36):26633-26644.

20. Kebache S, Cardin E, Nguyen DT, Chevet E, Larose L: Nck-1 antagonizes the endoplasmic reticulum stress-induced inhibition of translation. J Biol Chem 2004, 279(10):9662-9671.

21. Nguyen DT, Kebache S, Fazel A, Wong HN, Jenna S, Emadali A, Lee EH, Bergeron JJ, Kaufman RJ, Larose L, Chevet E: Nck-dependent activation of extracellular signal-regulated kinase-1 and regulation of cell survival during endoplasmic reticulum stress. Mol Biol Cell 2004, 15(9):4248-4260.

22. Yamani L, Latreille M, Larose L: Interaction of Nck1 and PERK phosphorylated at $Y(5)(6)(1)$ negatively modulates PERK activity and PERK regulation of pancreatic beta-cell proinsulin content. Mol Biol Cell 2014, 25(5):702-711.

23. Hetz C: The unfolded protein response: controlling cell fate decisions under ER stress and beyond. Nat Rev Mol Cell Biol 2012, 13(2):89-102.

24. Latreille M, Laberge MK, Bourret G, Yamani L, Larose L: Deletion of Nck1 attenuates hepatic ER stress signaling and improves glucose tolerance and insulin signaling in liver of obese mice. Am J Physiol Endocrinol Metab 2011, 300(3):E423-E434.

25. Puthanveetil $\mathrm{P}$, Wan $\mathrm{A}$, Rodrigues $\mathrm{B}$ : FoxO1 is crucial for sustaining cardiomyocyte metabolism and cell survival. Cardiovasc Res 2013, 97(3):393-403.

26. Matsumoto M, Pocai A, Rossetti L, Depinho RA, Accili D: Impaired regulation of hepatic glucose production in mice lacking the forkhead transcription factor Foxo1 in liver. Cell Metab 2007, 6(3):208-216.
27. Otsu M, Hiles I, Gout I, Fry MJ, Ruiz-Larrea F, Panayotou G, Thompson A, Dhand R, Hsuan J, Totty N, Smith AD, Morgan SJ, Courtneidge SA, Parker PJ, Waterfield MD: Characterization of two $85 \mathrm{kd}$ proteins that associate with receptor tyrosine kinases, middle-T/pp60c-src complexes, and PI3-kinase. Cell 1991, 65(1):91-104.

28. Huyer G, Liu S, Kelly J, Moffat J, Payette P, Kennedy B, Tsaprailis G, Gresser MJ, Ramachandran C: Mechanism of inhibition of protein-tyrosine phosphatases by vanadate and pervanadate. J Biol Chem 1997, 272(2):843-851.

29. Clemens JC, Ursuliak Z, Clemens KK, Price JV, Dixon JE: A Drosophila protein-tyrosine phosphatase associates with an adapter protein required for axonal guidance. J Biol Chem 1996, 271(29):17002-17005.

30. Ravichandran LV, Chen H, Li Y, Quon MJ: Phosphorylation of PTP1B at Ser (50) by Akt impairs its ability to dephosphorylate the insulin receptor. Mol Endocrinol 2001, 15(10):1768-1780.

31. Schneider-Poetsch T, Ju J, Eyler DE, Dang Y, Bhat S, Merrick WC, Green R, Shen B, Liu JO: Inhibition of eukaryotic translation elongation by cycloheximide and lactimidomycin. Nat Chem Biol 2010, 6(3):209-217.

32. Kenner KA, Anyanwu E, Olefsky JM, Kusari J: Protein-tyrosine phosphatase $1 B$ is a negative regulator of insulin- and insulin-like growth factor-I-stimulated signaling. J Biol Chem 1996, 271(33):19810-19816.

33. Stull AJ, Wang ZQ, Zhang XH, Yu Y, Johnson WD, Cefalu WT: Skeletal muscle protein tyrosine phosphatase $1 \mathrm{~B}$ regulates insulin sensitivity in African Americans. Diabetes 2012, 61(6):1415-1422.

34. Haj FG, Markova B, Klaman LD, Bohmer FD, Neel BG: Regulation of receptor tyrosine kinase signaling by protein tyrosine phosphatase-1B. J Biol Chem 2003, 278(2):739-744.

35. Dube N, Cheng A, Tremblay ML: The role of protein tyrosine phosphatase 1B in Ras signaling. Proc Natl Acad Sci U S A 2004, 101(7):1834-1839.

36. Frangioni JV, Beahm PH, Shifrin V, Jost CA, Neel BG: The nontransmembrane tyrosine phosphatase PTP-1B localizes to the endoplasmic reticulum via its 35 amino acid C-terminal sequence. Cell 1992, 68(3):545-560.

37. Issad T, Boute N, Boubekeur S, Lacasa D: Interaction of PTPB with the insulin receptor precursor during its biosynthesis in the endoplasmic reticulum. Biochimie 2005, 87(1):111-116.

38. Bettaieb A, Liu S, Xi Y, Nagata N, Matsuo K, Matsuo I, Chahed S, Bakke J, Keilhack H, Tiganis T, Haj FG: Differential regulation of endoplasmic reticulum stress by protein tyrosine phosphatase $1 \mathrm{~B}$ and $\mathrm{T}$ cell protein tyrosine phosphatase. J Biol Chem 2011, 286(11):9225-9235.

39. Gu F, Nguyen DT, Stuible M, Dube N, Tremblay ML, Chevet E: Protein-tyrosine phosphatase 1B potentiates IRE1 signaling during endoplasmic reticulum stress. J Biol Chem 2004, 279(48):49689-49693.

40. Bettaieb A, Matsuo K, Matsuo I, Wang S, Melhem R, Koromilas AE, Haj FG: Protein tyrosine phosphatase 1B deficiency potentiates PERK/elF2alpha signaling in brown adipocytes. PLOS One 2012, 7(4):e34412.

41. Kawasaki N, Asada R, Saito A, Kanemoto S, Imaizumi K: Obesity-induced endoplasmic reticulum stress causes chronic inflammation in adipose tissue. Sci Rep 2012, 2:799.

42. Ozcan U, Cao Q, Yilmaz E, Lee AH, Iwakoshi NN, Ozdelen E, Tuncman G, Gorgun C, Glimcher LH, Hotamisligil GS: Endoplasmic reticulum stress links obesity, insulin action, and type 2 diabetes. Science 2004, 306(5695):457-461.

43. Otoda T, Takamura T, Misu H, Ota T, Murata S, Hayashi H, Takayama H, Kikuchi A, Kanamori T, Shima KR, Lan F, Takeda T, Kurita S, Ishikura K, Kita Y, Iwayama K, Kato K, Uno M, Takeshita Y, Yamamoto M, Tokuyama K, Iseki S, Tanaka K, Kaneko S: Proteasome dysfunction mediates obesity-induced endoplasmic reticulum stress and insulin resistance in the liver. Diabetes 2013, 62(3):811-824.

44. Agouni A, Mody N, Owen C, Czopek A, Zimmer D, Bentires-Alj M, Bence KK, Delibegovic M: Liver-specific deletion of protein tyrosine phosphatase (PTP) 1B improves obesity- and pharmacologically induced endoplasmic reticulum stress. Biochem J 2011, 438(2):369-378.

45. Garrity PA, Rao Y, Salecker I, McGlade J, Pawson T, Zipursky SL: Drosophila photoreceptor axon guidance and targeting requires the dreadlocks SH2/SH3 adapter protein. Cell 1996, 85(5):639-650.

46. Rao Y, Zipursky SL: Domain requirements for the dock adapter protein in growth- cone signaling. Proc Natl Acad Sci U S A 1998, 95(5):2077-2082

47. Sparks AB, Quilliam LA, Thorn JM, Der CJ, Kay BK: Identification and characterization of Src SH3 ligands from phage-displayed random peptide libraries. J Biol Chem 1994, 269(39):23853-23856.

48. Cheadle C, Ivashchenko $Y$, South V, Searfoss GH, French S, Howk R, Ricca GA, Jaye M: Identification of a Src SH3 domain binding motif 
by screening a random phage display library. J Biol Chem 1994, 269(39):24034-24039.

49. Wu CL, Buszard B, Teng CH, Chen WL, Warr CG, Tiganis T, Meng TC: Dock/ Nck facilitates PTP61F/PTP1B regulation of insulin signalling. Biochem J 2011, 439(1):151-159.

50. Panzhinskiy E, Ren J, Nair S: Protein tyrosine phosphatase $1 \mathrm{~B}$ and insulin resistance: role of endoplasmic reticulum stress/reactive oxygen species/nuclear factor kappa B axis. PLoS One 2013, 8(10):e77228.

51. Frangioni JV, Oda A, Smith M, Salzman EW, Neel BG: Calpain-catalyzed cleavage and subcellular relocation of protein phosphotyrosine phosphatase 1B (PTP-1B) in human platelets. EMBO J 1993, 12(12):4843-4856.

52. Bartel DP: MicroRNAs: target recognition and regulatory functions. Cell 2009, 136(2):215-233.

53. Lerner AG, Upton JP, Praveen PV, Ghosh R, Nakagawa Y, Igbaria A, Shen $S$, Nguyen V, Backes BJ, Heiman M, Heintz N, Greengard P, Hui S, Tang $Q$ Trusina A, Oakes SA, Papa FR: IRE1alpha induces thioredoxin-interacting protein to activate the NLRP3 inflammasome and promote programmed cell death under irremediable ER stress. Cell metabolism 2012, 16(2):250-264.

54. Oslowski CM, Hara T, O'Sullivan-Murphy B, Kanekura K, Lu S, Hara M, Ishigaki S, Zhu LJ, Hayashi E, Hui ST, Greiner D, Kaufman RJ, Bortell R, Urano F: Thioredoxin-interacting protein mediates ER stress-induced beta cell death through initiation of the inflammasome. Cell metabolism 2012, 16(2):265-273

55. Upton JP, Wang L, Han D, Wang ES, Huskey NE, Lim L, Truitt M, McManus MT, Ruggero D, Goga A, Papa FR, Oakes SA: IRE1alpha cleaves select microRNAs during ER stress to derepress translation of proapoptotic Caspase-2. Science 2012, 338(6108):818-822.

56. Yang YM, Seo SY, Kim TH, Kim SG: Decrease of microRNA-122 causes hepatic insulin resistance by inducing protein tyrosine phosphatase 1B, which is reversed by licorice flavonoid. Hepatology 2012, 56(6):2209-2220.

57. Barr AJ: Protein tyrosine phosphatases as drug targets: strategies and challenges of inhibitor development. Future Med Chem 2010, 2(10):1563-1576.

58. Tonks NK: Protein tyrosine phosphatases-from housekeeping enzymes to master regulators of signal transduction. FEBS J 2013, 280(2):346-378

59. Bladt F, Aippersbach E, Gelkop S, Strasser GA, Nash P, Tafuri A, Gertler $\mathrm{FB}$, Pawson T: The murine Nck SH2/SH3 adaptors are important for the development of mesoderm-derived embryonic structures and for regulating the cellular actin network. Mol Cell Biol 2003, 23(13):4586-4597.

60. Renton KW, Deloria LB, Mannering GJ: Effects of polyribonoinosinic acid polyribocytidylic acid and a mouse interferon preparation on cytochrome P-450-dependent monooxygenase systems in cultures of primary mouse hepatocytes. Mol Pharmacol 1978, 14(4):672-681.

61. Mounier C, Dumas V, Posner BI: Regulation of hepatic insulin-like growth factor-binding protein-1 gene expression by insulin: central role for mammalian target of rapamycin independent of forkhead box O proteins. Endocrinology 2006, 147(5):2383-2391.

\section{Submit your next manuscript to BioMed Central and take full advantage of:}

- Convenient online submission

- Thorough peer review

- No space constraints or color figure charges

- Immediate publication on acceptance

- Inclusion in PubMed, CAS, Scopus and Google Scholar

- Research which is freely available for redistribution 